\title{
Effectiveness of commercial harvesting in controlling feral-pig populations
}

\author{
Matthew Gentle ${ }^{\mathrm{A}, \mathrm{C}}$ and Anthony Pople ${ }^{\mathrm{B}}$ \\ A Robert Wicks Pest Animal Research Centre, Biosecurity Queensland, Department of Agriculture, \\ Fisheries and Forestry, 203 Tor Street, Toowoomba, Qld 4350, Australia. \\ ${ }^{B}$ Invasive Plant and Animal Science, Biosecurity Queensland, Department of Agriculture, Fisheries and Forestry, \\ Queensland, Ecosciences Precinct, GPO Box 267, Brisbane, Qld 4001, Australia. \\ ${ }^{\mathrm{C} C}$ Corresponding author. Email: matthew.gentle@daff.qld.gov.au
}

\begin{abstract}
Context. The feral pig (Sus scrofa) is a widespread pest species in Australia and its populations are commonly controlled to reduce damage to agriculture and the environment. Feral pigs are also a resource and harvested for commercial export as game meat. Although many other control techniques are used, commercial harvesting of feral pigs is often encouraged by land managers, because it carries little or no cost and is widely perceived to control populations.

Aims. To use feral-pig harvesting records, density data and simple harvest models to examine the effectiveness of commercial harvesting to reduce feral-pig populations.

Methods. The present study examined commercial harvest off-take on six sites $\left(246-657 \mathrm{~km}^{2}\right)$ in southern Queensland, and 20 large blocks $\left(\sim 2-6000 \mathrm{~km}^{2}\right)$ throughout Queensland. The harvest off-take for each site was divided by monthly or average annual population size, determined by aerial survey, to calculate monthly and annual harvest rates. A simple harvest model assuming logistic population growth was used to determine the likely effectiveness of harvesting.

Key results. Commercial harvest rates were generally low $(<\sim 20 \%)$ and are likely to provide only modest reductions in population size. Additionally, harvest rates capable of substantial reductions $(>50 \%)$ in long-term population size were isolated occurrences and not maintained across sites and years. High harvest rates were observed only at low densities. Although these harvest rates may be sufficiently high to hold populations at low densities, the population is likely to escape this entrapment following a flush in food supply or a reduction in harvest effort.

Implications. Our results demonstrated that, at current harvest rates, commercial harvesting is ineffective for the landscape-scale control of feral-pig populations. Unless harvest rates can be significantly increased, commercial harvesting should be used as a supplement to, rather than as a substitute for, other damage-control techniques.
\end{abstract}

Additional keywords: density, harvesting, management.

Received 29 May 2013, accepted 16 September 2013, published online 11 October 2013

\section{Introduction}

The feral pig (Sus scrofa) is a well known introduced species found throughout much of Australia. In some areas, particularly Queensland and New South Wales, feral pigs are targeted by accredited, commercial operators for supply to the game-meat industry. Feral pigs are harvested mostly through ground shooting (with animals often located through the use of hunting dogs), but many are also live-trapped before being shot. Animals are then partly eviscerated, and transported to a local field 'chiller' depot for refrigeration. Carcasses are then delivered to a licenced game-meat processer for post-mortem inspection, processing and export as 'Australian wild pig' to mainly European countries for consumption (Ramsay 1994; Forsyth and Parkes 2004). Despite their resource value, feral pigs remain a major economic pest (Choquenot et al. 1996), thought to cause in excess of A $\$ 100$ million in lost agricultural production in Australia per annum (McLeod 2004). Recent assessments using economic surplus models have suggested costs to the grain, lamb and wool industries of A $\$ 9.2$ million per annum (Gong et al. 2009). Most production damage is reportedly through predation on stock including lambs (e.g. Pavlov et al. 1981) and damaging grain and other crops (Benson 1980). Feral pigs are also responsible for a range of environmental impacts, including predation of native species, and disturbance or destruction of natural habitats (Caughley 1994; Fordham et al. 2006; Mitchell 2008). Although the true cost of this damage is unknown and varies temporally and spatially, the damage ultimately triggers control by land managers. Common techniques utilised to reduce pig density (and resulting impacts) include 1080 baiting, trapping, aerial and ground shooting and commercial and recreational harvesting (Mitchell 2010; Bengsen et al. 2013), which vary in efficacy 
and cost. Land managers will invest resources in control when they believe the benefits of control (i.e. reduced losses in crop yield or animal production) outweigh the costs. However, commercial and recreational harvesting of feral pigs is seen to offer control that is essentially 'free', while providing a sustainable off-take for the game-meat industry (Ramsay 1994). Although the motivation of the commercial harvesting industry is ultimately profit-driven (rather than reducing pig density per se), the widely held perception of effective, 'free' control can favour the use of harvesting, rather than other forms of conventional lethal control, by land managers aiming to control pig populations.

Simple harvest models can be used to assess the efficacy of harvesting through determining (1) the likely level of population reduction for a particular harvest rate, and (2) whether that harvest rate is sustainable in the long term. When a population is at a density well below carrying capacity $(K)$ and growth is unrestricted, $r_{\text {obs }}$ (the observed rate of increase) is likely to approach its $r_{\max }$ (the maximum rate of increase; Caughley 1980). Published maximum rates of increase calculated for Australian feral-pig populations range between 0.57 and 0.78 (0.57, Hone and Pedersen 1980; 0.6-0.7, Giles 1980; 0.78, Caley 1993; 0.69, Choquenot 1998; 0.74, Hone 2002). These are consistent with expectations based on body size and age at first reproduction (Hone et al. 2010; Hone 2012), and indicate a potential doubling time of 12 months for a feral-pig population. For a population potentially growing at $r_{\max }, 60-70 \%$ of the population needs to be removed continuously throughout the year (= instantaneous rate of harvest, Caughley 1980) to hold it stable. If there is a single removal (= isolated rate of harvest, Caughley 1980), such as through baiting, then $\sim 50 \%$ of the population needs to be removed to hold it stable.

However, for a population to increase at $r_{\max }$ there need to be unlimited resources (and no predation or emigration), which may occur when a population has been reduced to low density. Rate of increase is expected to decline with increasing density as the population recovers. Assuming logistic population growth, the relationship between harvest rate, sustained yield and depression of $N$ for a feral-pig population where $r_{\max }=0.69$ is shown in Fig. 1. As the population is reduced, it will generate a rate of increase and that productivity (i.e. $r \times N$ ) can be harvested sustainably to hold the population at the lowered density.

From Fig. 1, the maximum sustainable yield (MSY) is taken at $K / 2$ at a harvest rate of $r_{\max } / 2$ (Caughley 1980). Other sustainable harvest rates are clearly possible, resulting in equilibrium densities between 0 and $K$ and sustained yields of $<\mathrm{MSY}$. These are the implications of harvesting at constant rates in the long term. Other sustainable strategies are possible, such as short periods of heavy harvesting, followed by periods of no harvesting to allow the population to recover.

The logistic model is simplistic because the rate of increase will be very weakly related to density in semiarid environments. Rates of population increase of feral pigs appear to be strongly dependent on survival rates of juveniles (e.g. Giles 1980). Sows cease to lactate when their crude protein intake drops below critical levels (Giles 1980; Pavlov 1980), resulting in high mortality of piglets (Caley 1993). Rainfall is an important determinant of plant growth, and therefore protein contents. In reality, then, potential rate of increase is likely to be a function of food supply driven by rainfall (Giles 1980; Caley 1993; Woodall 1983; Choquenot 1998), with $r_{\max }$ possible after flooding rainfall. In such fluctuating environments, the yield curve in Fig. 1a will be lower and the MSY shifted to the left (Grigg and Pople 2001) for a predominantly herbivorous feralpig population (Giles 1980).

The efficacy of harvesting is recognised as much lower than poison baiting (Allen et al. 1995) where large, immediate knockdowns in population size can be achieved, but harvesting may still be able to restrict population growth, particularly when densities are low. The potential impact of harvesting and/or control on feral-pig populations has been explored in theory (see Choquenot et al. 1995; Hone 2012), but empirical data are lacking. The present study examines commercial harvest off-take on six study sites in southern Queensland, to determine the ability of commercial harvesting to control feral-pig populations. These data were also compared with commercial harvest off-take elsewhere in Queensland to gain some general understanding of the likely effectiveness of harvesting as a control method.

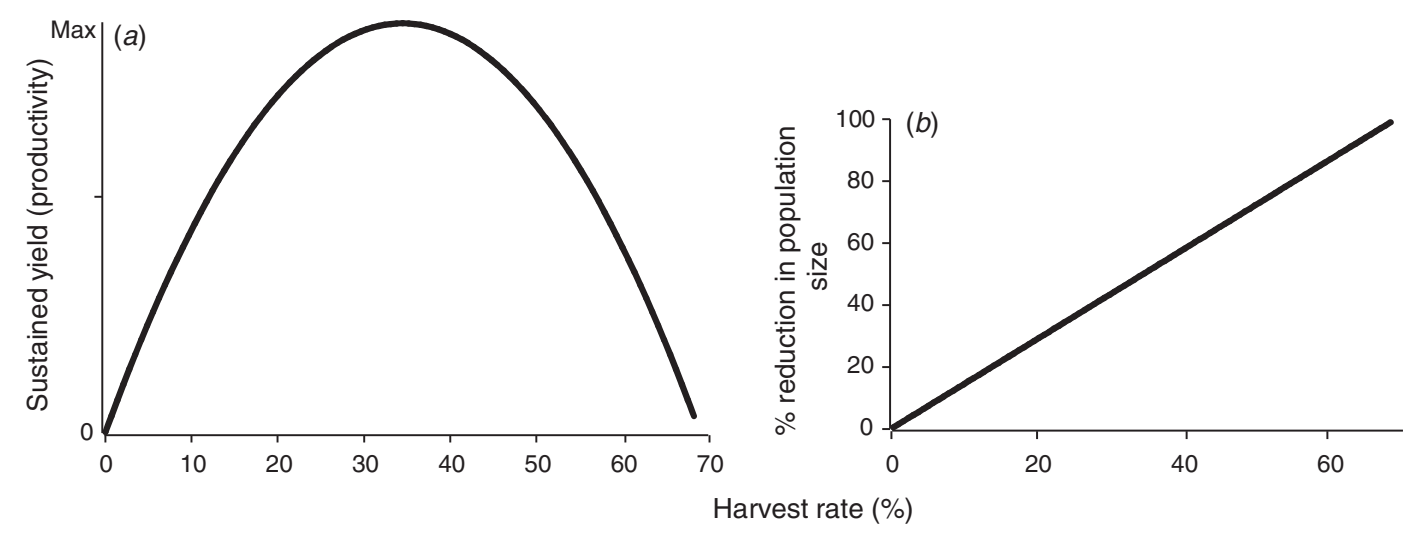

Fig. 1. (a) Sustained yield curve for a feral-pig population that grows logistically with $r_{\max }=0.69$. (b) The \% reduction in population size from long-term harvesting of the population at constant instantaneous rates of $0-69 \%$. 


\section{Materials and methods}

\section{Queensland Murray-Darling Catchment sites}

Six study sites, ranging from 246 to $657 \mathrm{~km}^{2}$ in area, were located in the Queensland Murray-Darling Catchment (QMDC) of south-western Queensland (Fig. 2b). Each site consisted of several properties producing sheep, cattle or mixed cereal or fibre (cotton) crops, often in combination. Habitats were typically fragmented, containing areas of cultivation, large tracts of grazing land with the occasional forest or woodland verges, particularly along riparian areas. These sites are representative of the grain-producing belt throughout southern Queensland and northern New South Wales where feral-pig harvesting commonly occurs and is encouraged by landholders. It is one of the main areas of commercial harvesting of feral pigs because its relatively consistent supply of pigs and close proximity to processing facilities, reducing freight costs (C. Dee, Wild Game Resources, pers. comm. 2011).

\section{Aerial surveys}

Broad-scale, repeatable estimates of absolute density were required to estimate harvest rate and to compare densities over time and among locations. Aerial surveys were flown to estimate feral pig density and distance-sampling methods (Buckland et al. 1993) used to adjust counts for visibility bias. In all, 8-10 parallel east-west transects were systematically placed $5 \mathrm{~km}$ apart across the six study sites. A Robinson R44 helicopter, with the two rear doors removed, was flown at a ground speed of $93 \mathrm{~km} \mathrm{~h}^{-1}(50 \mathrm{kts})$ and at a height of $61 \mathrm{~m}(200 \mathrm{ft})$ above the ground. Navigation was by a global positioning system (GPS) receiver. Observers, occupying the two rear seats of the helicopter, counted the pigs seen on either side of the aircraft. To enable data to be analysed as line transects, clusters of animals were recorded, using a digital hand-held recorder, into the $0-20-\mathrm{m}, 20-40-\mathrm{m}$, 40-70-m, 70-100-m, 100-150-m and >150-m distance classes, perpendicular to the transect line. Interval width increased with distance to reflect the greater importance of accurate measurements near the transect line and to aid modelling the shoulder in the detection function (Buckland et al. 1993). The distance classes to $150 \mathrm{~m}$ were delineated on aluminium booms extending from either side of the helicopter. Animals were recorded in the position that they were first seen, avoiding problems with animals moving in response to the helicopter (Fewster et al. 2008).

The seating of the rear-seat observers was allocated randomly for each survey session. There was a third observer seated in the front left when weight or training restrictions permitted. Several observers were used during the course of the study, but all were either experienced at counting pigs from the air or spent 'training' time in the front seat until their counts were close to that of an experienced observer (Beard 1999). Aerial surveys were conducted on all six QMDC sites in the months of March/April, August and November, with eight surveys flown between November 2007 and April 2010. All

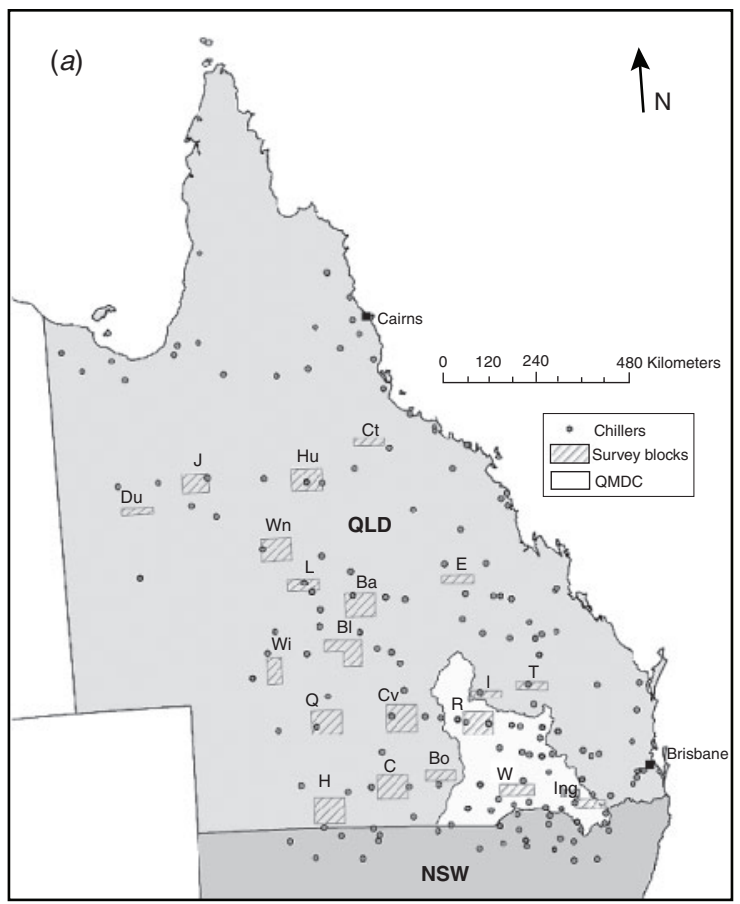

(b)

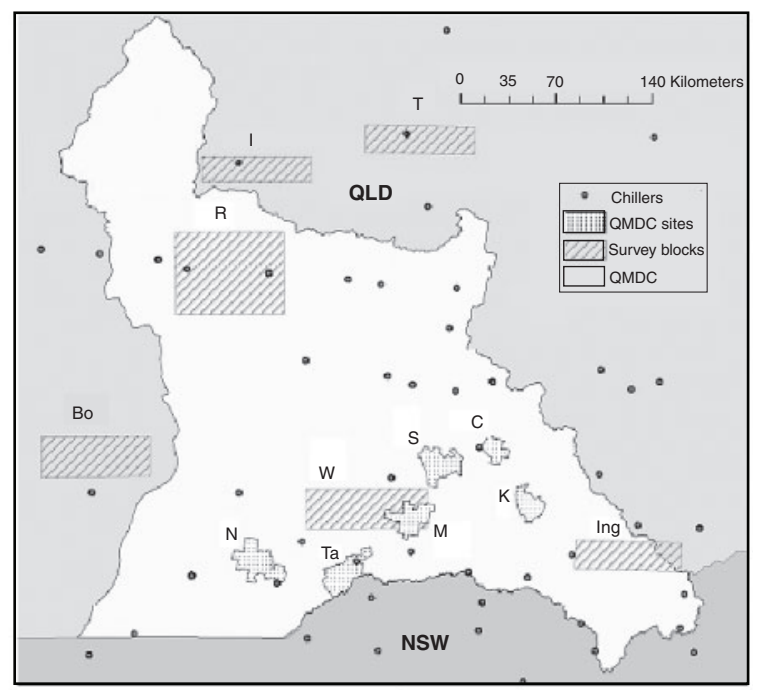

Fig. 2. (a) Location of regional survey blocks used to monitor feral-pig populations in Queensland (Qld). J = Julia Creek; Du=Duchess; $\mathrm{Ct}=$ Charters Towers; $\mathrm{Hu}=$ Hughenden; $\mathrm{Wn}=$ Winton; $\mathrm{L}=$ Longreach; $\mathrm{Ba}=$ Barcaldine; $\mathrm{E}=$ Emerald; $\mathrm{Bk}=\mathrm{Blackall} ; \mathrm{Wi}=\mathrm{Windorah}$; $\mathrm{Q}=$ Quilpie; $\mathrm{CV}=$ Charleville; $\mathrm{H}=$ Hungerford; $\mathrm{C}=$ Cunnamulla; $\mathrm{Bo}=$ Bollon; $\mathrm{R}=$ Roma; $\mathrm{I}=$ Injune; $\mathrm{T}=$ Taroom; $\mathrm{W}=\mathrm{Westmar}$; Ing = Inglewood. Location of field chillers in Queensland and northern New South Wales (NSW) are also shown. (b) Location of field chillers, regional survey blocks and Queensland Murray-Darling Catchment (QMDC) sites used to monitor pig populations in QMDC area. QMDC sites: $\mathrm{N}=$ Nindigully; $\mathrm{Ta}=$ Talwood; $\mathrm{M}=$ Minnel; $\mathrm{S}=$ Southwood; $\mathrm{C}=$ Crowders; $\mathrm{K}=$ Kindon; Survey blocks: $\mathrm{Bo}=\mathrm{Bollon}$; $\mathrm{R}=$ Roma; $\mathrm{I}=$ Injune; $\mathrm{T}=$ Taroom; $\mathrm{W}=$ Westmar; Ing = Inglewood. 
surveys were conducted within either $2 \mathrm{~h}$ after sunrise or $2 \mathrm{~h}$ before sunset. This technique has now become an established method for broad-scale surveys of macropods and other large vertebrates in eastern Australia (e.g. Clancy et al. 1997), including pigs, but not always using line transect sampling (Choquenot 1995; Tracey 2006).

The two left-side observers counted simultaneously, allowing mark-recapture line-transect (MRLT) methods (Laake and Borchers 2004; Laake et al. 2008) to be employed for at least some surveys. Their sightings were separated into those seen by both observers and those seen only by the front observer or only by the rear observer. This was identified by the recorded time of the sighting, the size of the group and its distance class. MRLT methods allow assessment of and correction for the key assumption of line transects, that animals are detected on the line with certainty. For the mark-recapture component, the key assumption is that detections of the two left-side observers are independent (see Laake et al. 2008).

\section{Regional survey blocks}

Kangaroo harvesting is regulated largely through the use of quotas set from proportions of estimated population size (e.g. Pople et al.2010). To monitor kangaroo densities, the Queensland Department of Environment and Heritage Protection (DEHP) regularly undertakes aerial surveys in survey blocks $\left(\sim 2-6000 \mathrm{~km}^{2}\right)$ throughout the state, but concentrated in the sheep rangelands (Fig. 2; Caughley 1987). Feral pigs are also counted on these surveys using identical survey techniques (i.e. helicopter type, speed, altitude, distance classes, and the use of highly trained observers) to those on the QMDC study sites. Under the current management program, four of the blocks (Charleville, Blackall, Barcaldine and Windorah) are surveyed annually, with the remainder flown every second year. The latter blocks are paired with another block in the same bioregion and one of each pair flown is flown in alternate years. All blocks are flown every 5 th year.

\section{Density estimation}

\section{QMDC sites}

To calculate feral-pig densities, two separate analyses were performed in DISTANCE 6.0 (Thomas et al. 2010). First, MRLT data were used to calculate an estimate of the probability of detecting a cluster of pigs on the line, $g(0)$, and its standard error. Second, rear-observer counts were analysed as conventional line-transect (CLT) sampling, with the resulting density and variance estimates adjusted for $g(0)$, and its standard error determined from the MRLT analysis.

For the MRLT analysis, point independence was assumed (Laake et al. 2008) and separate detection functions were modelled for the line transect data and for the mark-recapture data, although modelling of only the latter was required for an estimate of $g(0)$. For comparison with the CLT analysis below, the line-transect data were modelled using both half-normal and hazard-rate key functions, with cluster size as a potential covariate. For the mark-recapture data, distance, observer (front or rear) and cluster size were potential covariates in a logistic function. Models were compared using Akaike's information criterion (AIC).
For the CLT analysis, the following five detection function models were considered: a uniform key function, plus either a cosine or simple polynomial series expansion; a half-normal key function, plus either a cosine or a Hermite polynomial series expansion; and a hazard-rate key function, plus a cosine series expansion. The most parsimonious model and number of adjustment terms in the series expansion were selected using AIC. Detection functions with marked spikes at zero distance were rejected. Separate estimates were calculated for each site for each survey. Sample sizes were too small $(<50)$ to calculate separate detection functions in each case, so a detection function was modelled using data pooled across all sites and surveys.

Densities of pigs were calculated as densities of clusters multiplied by mean cluster size. Variance formulae are given by Buckland et al. (1993).

\section{Regional survey blocks}

Data from 20 regional survey blocks were analysed. It was assumed that detection probability would vary primarily among block and then, secondarily, among years. However, small sample sizes on many blocks, particularly those with abbreviated time series, forced detection functions to be modelled by pooling data across nearby blocks. Block-specific detection functions were modelled for Blackall and Bollon. All counts were analysed as CLT sampling, but again with density and variance estimates adjusted for $g(0)$ and its standard error determined from the MRLT analysis of the QMDC site data described above.

\section{Commercial harvesting}

The harvest off-take (i.e. the number of feral pigs removed) from each study site was estimated from the records of companies processing feral-pig carcasses. Game-processing companies provided details of the location of harvesting chillers throughout Queensland and northern New South Wales, and the numbers of feral pigs processed in each of these chillers for the period June 2007 - July 2010. Data were collated and imported into ArcGIS ${ }^{\odot}$ (ESRI Inc., CA, USA) for spatial analyses. Each chiller location and corresponding harvest data were matched to the respective spatial location. Unlike kangaroo harvesting, properties where pigs are harvested are not identified by feral-pig processors. Choquenot et al. (1995) argued from modelled data that it is economically profitable to harvest feral pigs out to $72 \mathrm{~km}$ from a chiller. Kangaroo harvesters are known to travel up to $\sim 150 \mathrm{~km}$ from each chiller location (Hacker et al. 2003). Harvest density should decrease with increasing distance from a chiller (Choquenot et al. 1995), so we assumed that $75 \%$ of the harvested total for each chiller occurred within a $75-\mathrm{km}$ radius, with the remainder $(25 \%)$ occurring $75-150 \mathrm{~km}$ from a chiller. As no data exist to verify this assumption, this seemed the most reasonable approach because there are obvious constraints. Harvesters are constrained to take pigs close to a chiller because there is both a travelling cost and a requirement to deposit carcasses at the chiller within $2 \mathrm{~h}$ of sunrise. The harvest was assumed to be uniform within the landscape in each buffered area. The proportion of each of the six study sites that overlapped each buffered area (i.e. 75- and 150-km buffers) was then determined. 
This proportion was used to estimate the number of pigs from each chiller that were harvested from each study site. We summed this commercial harvest off-take each month and year for each study site. Annual estimates for 2007 and 2010 were calculated by using the monthly average of the available 7 months of data for each month of the missing period.

The harvest off-take was divided by monthly or average annual population size, determined by aerial survey, to calculate monthly and annual harvest rates, as percentages of the population harvested.

Harvest off-take and annual harvest rates for feral pigs were similarly calculated for the regional survey blocks.

\section{Harvest rates and effectiveness of harvesting}

The effectiveness of commercial harvesting was also investigated by comparing actual and potential (without commercial harvesting) rates of increase on the QMDC sites. The rate of increase of feral pigs was calculated as

$$
r=\ln \left(D_{\mathrm{t}+1} / D_{\mathrm{t}}\right),
$$

where $D_{\mathrm{t}}$ and $D_{\mathrm{t}+1}$ are estimates of population density from each survey. The instantaneous commercial harvest rate (chr) between consecutive density estimates was calculated as

$$
c h r=-\ln \left(1-\frac{c h}{\sqrt{D_{t} D_{t+1}}}\right),
$$

where $c h$ is the commercial harvest off-take between surveys based on processor records. An instantaneous rate is appropriate because harvesting was essentially a continuous activity through time rather than isolated events (see Caughley 1980). The potential rate of increase $\left(r_{\mathrm{p}}\right)$ was adjusted for the harvested mortality rate and calculated as

$$
r_{\mathrm{p}}=r+c h r
$$

Calculating $r_{\mathrm{p}}$ using this method assumes that mortality from harvesting is additional to natural mortality rather than compensatory to some extent. Rates of increase were also compared with zero using two-group randomisation tests (Manly 1991).

\section{Results}

\section{Feral-pig-density estimation}

For the MRLT analysis $(n=106)$, the most parsimonious mark-recapture model contained only the intercept (i.e. no covariates). Models including observer, cluster size or distance alone as covariates appeared plausible with $\Delta \mathrm{AIC}<2$. However, in all cases, parameters were not significant, so the model with only the intercept was used and no model averaging was considered. This yielded an estimate of $g(0)$ of $0.64 \pm 0.04$, indicating that only two-thirds of pig groups were seen on the transect line. A half-normal detection function was preferred over a hazard function for the line-transect data, producing an average detection probability in the strip of $0.27 \pm 0.02$. Including cluster size as a covariate produced a plausible model $(\triangle \mathrm{AIC}=2)$, but again the parameter estimate was not significant.
For the CLT analysis, groups of feral pigs $(n=290)$ were detected with a probability of $P=0.29 \pm 0.01$, with detection probability declining rapidly beyond $40 \mathrm{~m}$ (Fig. 3). This result

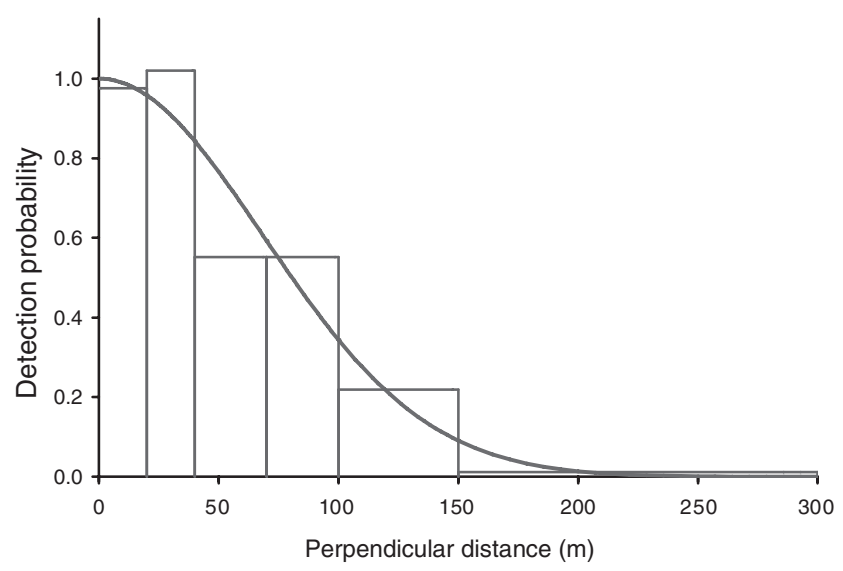

Fig. 3. Half-normal detection function for groups of feral pigs $(n=290)$ pooled across all study sites and sampling periods.

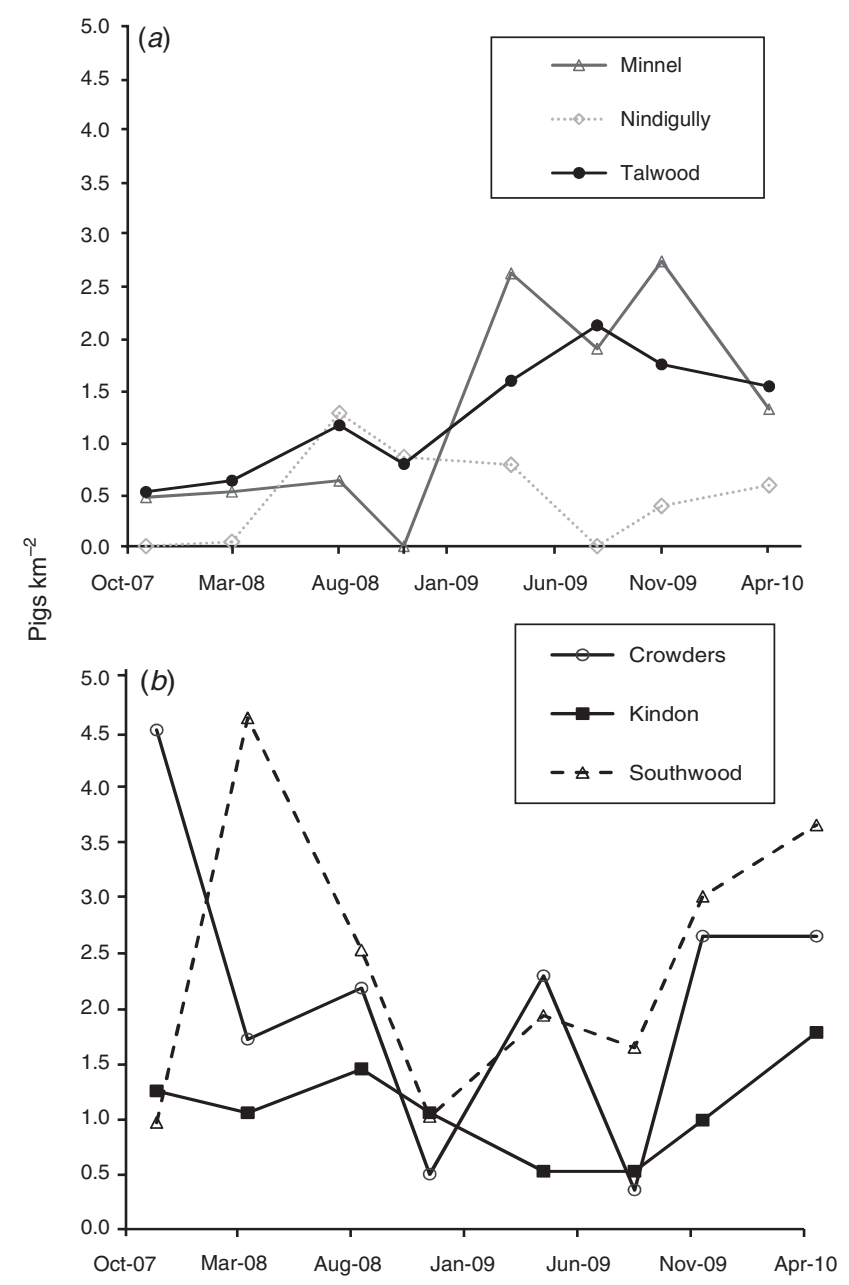

Fig. 4. $(a, b)$ Density of feral pigs (pigs $\mathrm{km}^{-2}$ ) on the Queensland Murray-Darling Catchment (QMDC) study sites for each survey period, from November 2007 to April 2010. 
is almost identical to that recorded in the MRLT analysis with a smaller sample size.

Density estimates for the QMDC sites from the DISTANCE analyses are shown in Fig. 4, and are provided in Table S1, available as Supplementary material for this paper. Feral-pig density on the QMDC sites generally ranged between 0.5 and 2 pigs $\mathrm{km}^{-2}$. Density estimates for sites from each survey period are obviously highly dependent on recording feral pigs when they are present. For example, no feral pigs were observed at Nindigully during the November 2007 and August 2009 survey periods, resulting in zero density estimates. At the time of sampling, feral pigs were known to be present, but were not detected for the given survey effort. At these levels of survey effort, it is difficult to derive accurate and precise density estimates when densities are low (here appearing to be $<0.05$ pigs $\mathrm{km}^{-2}$ ) and few groups are observed. More reliable estimates from QMDC study sites are those averaged over consecutive survey periods, where multiple surveys were undertaken for each year (Table S1). Precision is still poor, but sufficient to distinguish the density extremes on the sites.

Differences in survey locations and timings preclude direct comparisons between data-collection methods used on the QMDC sites and regional survey blocks. However, similar densities on the partially overlapping Minnel (up to 2.74 pigs $\mathrm{km}^{-2}$ ) site and Westmar (up to 2.07 pigs $\mathrm{km}^{-2}$ ) block during the

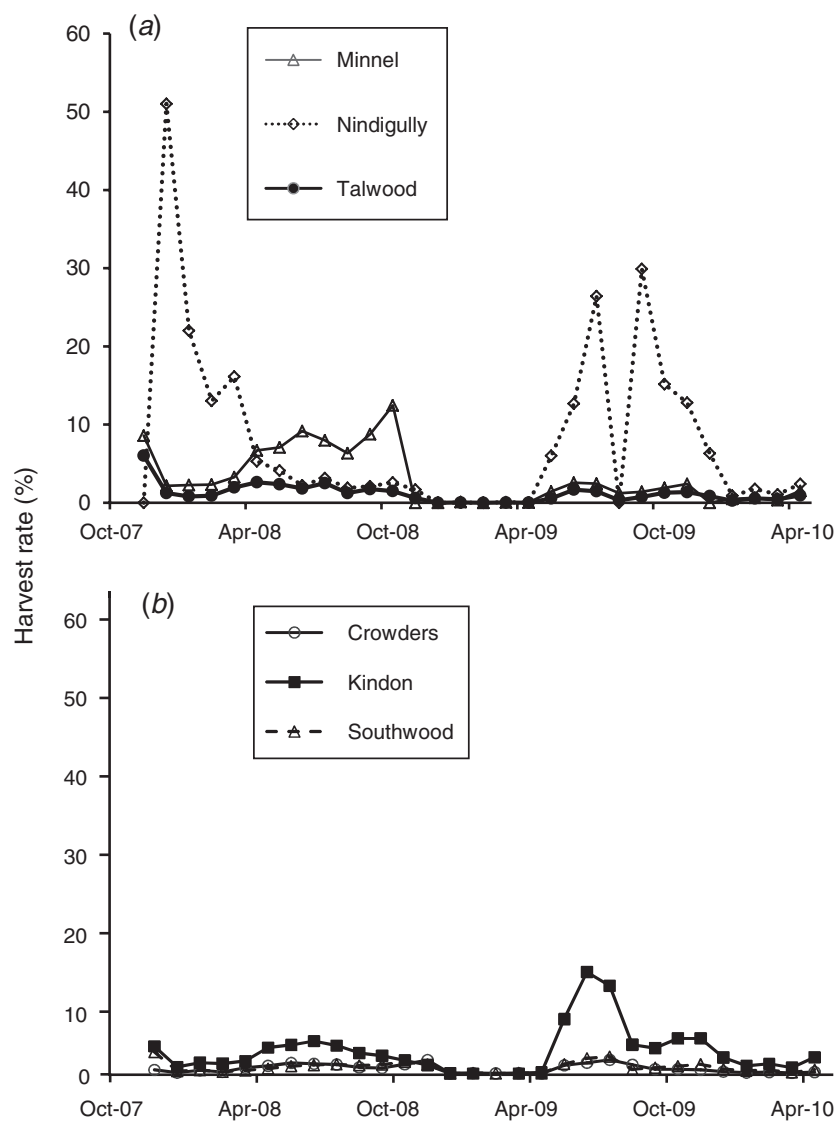

Fig. 5. $(a, b)$ Monthly commercial harvest rate (\%) for the six Queensland Murray-Darling Catchment (QMDC) study sites from November 2007 to April 2010.
2008-10 survey periods suggest that methods were comparable. Density estimates for each survey and average density estimates for the regional survey blocks from surveys immediately before and during the study period are provided in Table S2, available as Supplementary material for this paper.

\section{Commercial harvest rates}

Data from all four processing companies operating field chillers (Fig. 2) in Queensland $(n=140)$ and northern New South Wales $(n=24)$ were collated to determine harvest off-take. Buffering of each aerial survey site through GIS analyses indicated that QMDC sites appear to be well serviced by the network of chillers. In total, 21 chillers were located within $75 \mathrm{~km}$ of the QMDC sites, and 49 chillers within $150 \mathrm{~km}$. Individual sites had at least six, and up to nine, chillers available within $75 \mathrm{~km}$ $($ mean $=7.5$, s.d. $=1.0)$, and between 22 and 31 chillers within $150 \mathrm{~km}($ mean $=28$, s.d. $=3.4)$.

Harvest rates among the six QMDC sites varied considerably (Figs 5 and 6). The yearly mean for all sites declined over the

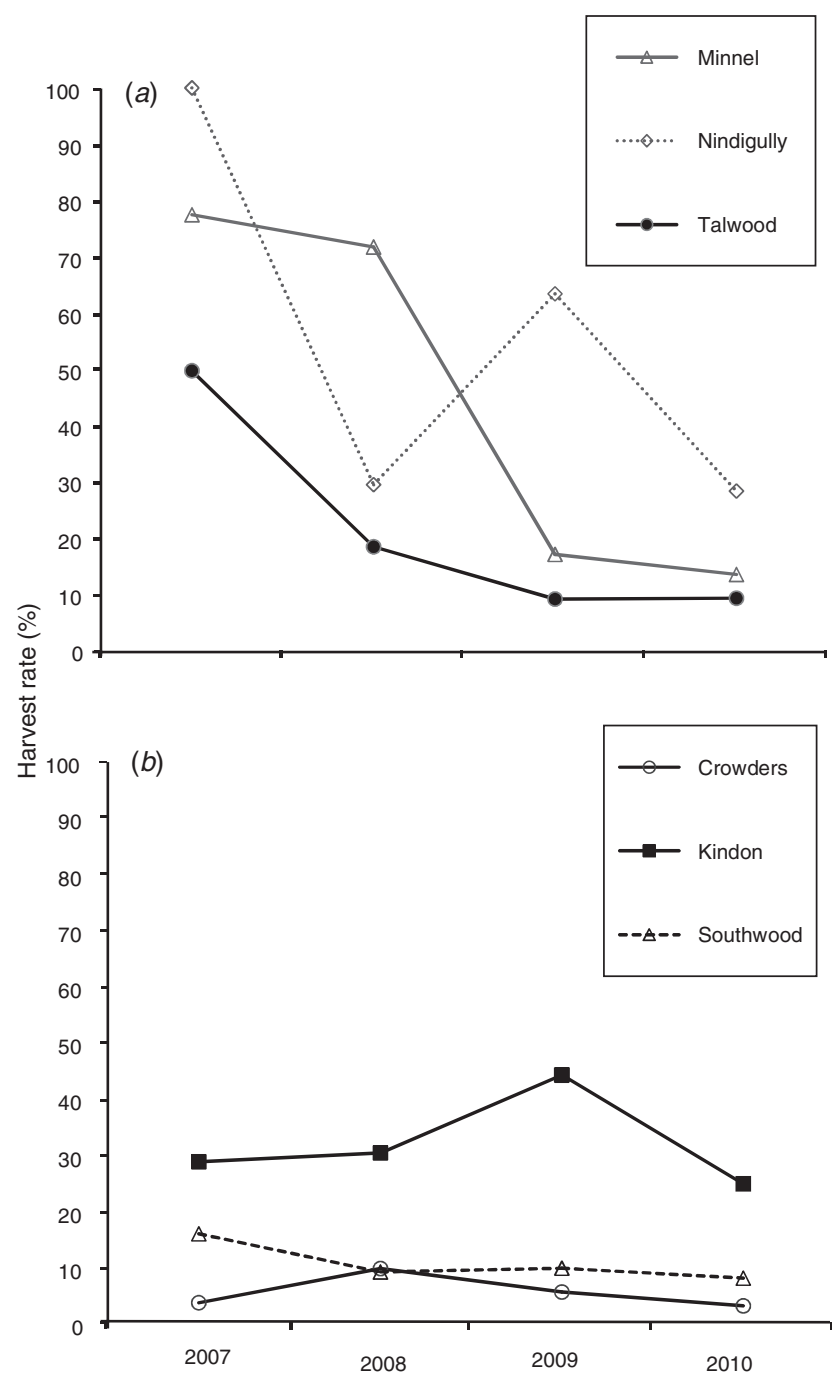

Fig. 6. $(a, b)$ Annual commercial harvest rates for the six Queensland Murray-Darling Catchment (QMDC) study sites for 2007-10. 
4 years, from $46.0 \%$ to $14.5 \%$. Minnel and Nindigully had, on average, the greatest harvest rate over the study period (2007-10), with an average of $44.9 \%$ and $55.2 \%$, respectively, of the population removed by commercial harvesters during this period. Crowders Creek had the lowest harvest rate, not exceeding $10 \%$ over $2007-10$.

The Queensland regional survey blocks were, on the whole, more isolated from field chillers. Each block, on average, had 4.5 chillers $<75 \mathrm{~km}($ s.d. $=2.8)$ and 12.0 chillers $<150 \mathrm{~km}($ s.d. $=7.6)$, and this tended to increase with latitude, reflecting the largely southern Queensland distribution of chillers (see Fig. 2). Similar to the QMDC sites, the harvest rate (\% of animals harvested) at each of the regional survey blocks varied considerably, ranging between an average of 2.2\% (Quilpie) and 95.5\% (Duchess) of the population being harvested and sent to chillers each year (Fig. 7). Some of the higher estimates of harvest rate (e.g. Emerald and Hughenden) are likely overestimates because of low and imprecise population estimates based on small sample sizes and a patchy dispersion of feral pigs in the survey block.

\section{Harvesting effectiveness}

The sustained-yield curve (Fig. 1) assuming logistic population growth suggested a MSY of $\sim 35 \%$, resulting in a long-term reduction in population size of $\sim 50 \%$. The harvest rates for the QMDC sites shown in Fig. 6 were generally below the MSY, usually between $10 \%$ and $30 \%$, and such an off-take in the longterm would result in a $\sim 15-44 \%$ reduction in population size. Similarly, the harvest rates for the regional survey blocks were generally below $20 \%$, with an associated reduction in population size of $<30 \%$. These harvest rates need to be maintained over several years for these reductions to be realised.

Figures 8 and 9 show a pattern of harvest rate being greatest for low-density populations (in the QMDC, at densities lower than $\sim 1$ pig km$~^{-2}$; in the regional survey blocks, at densities lower than $\sim 0.4$ pigs $\mathrm{km}^{-2}$ ), but declining rapidly with increasing density. This pattern is consistent among sites (Fig. 8a) and among years (Figs 8b, 9). Clearly, for the years examined, high harvest rates are not being maintained at higher feral-pig density, allowing populations to recover.

The number of animals harvested per $100 \mathrm{~km}^{2}$ on the QMDC sites (Fig. 10) and regional survey blocks (Fig. 11) is not correlated with feral-pig density, suggesting that factors other than pig density are determining harvest off-take. These factors will be either supply-limited (e.g. limited number of harvesters who cannot reduce their search and handling time; restricted access to animals because of vegetation or road network) or demand-limited (e.g. restrictions on the number of carcasses received by processers through price, quotas or chiller-box closures).

Given the number of feral pigs removed commercially from the QMDC sites, we calculated the potential rate of increase $\left(r_{\mathrm{p}}\right)$ in the absence of harvest mortality. The rate of increase and potential rate of increase for the QMDC sites are shown in Table 1. The difference between the potential and observed rates of increase suggests that commercial harvesting contributed little to the maintenance of low feral-pig numbers
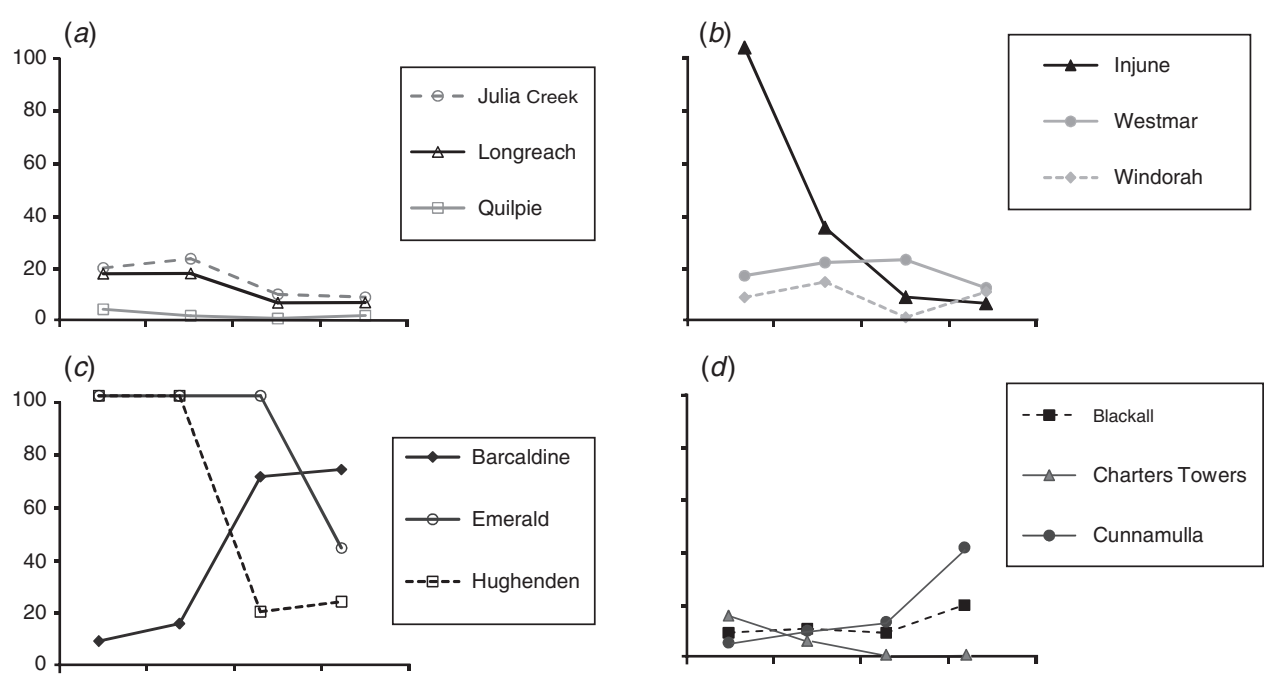

(e)

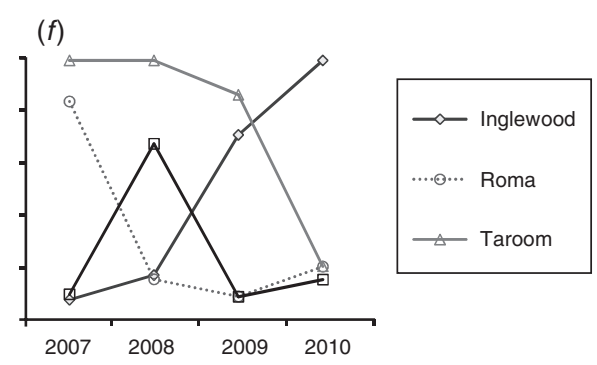

Fig. 7. (a-f) Annual harvest rates (\%) for the regional survey blocks for 2007-10. 


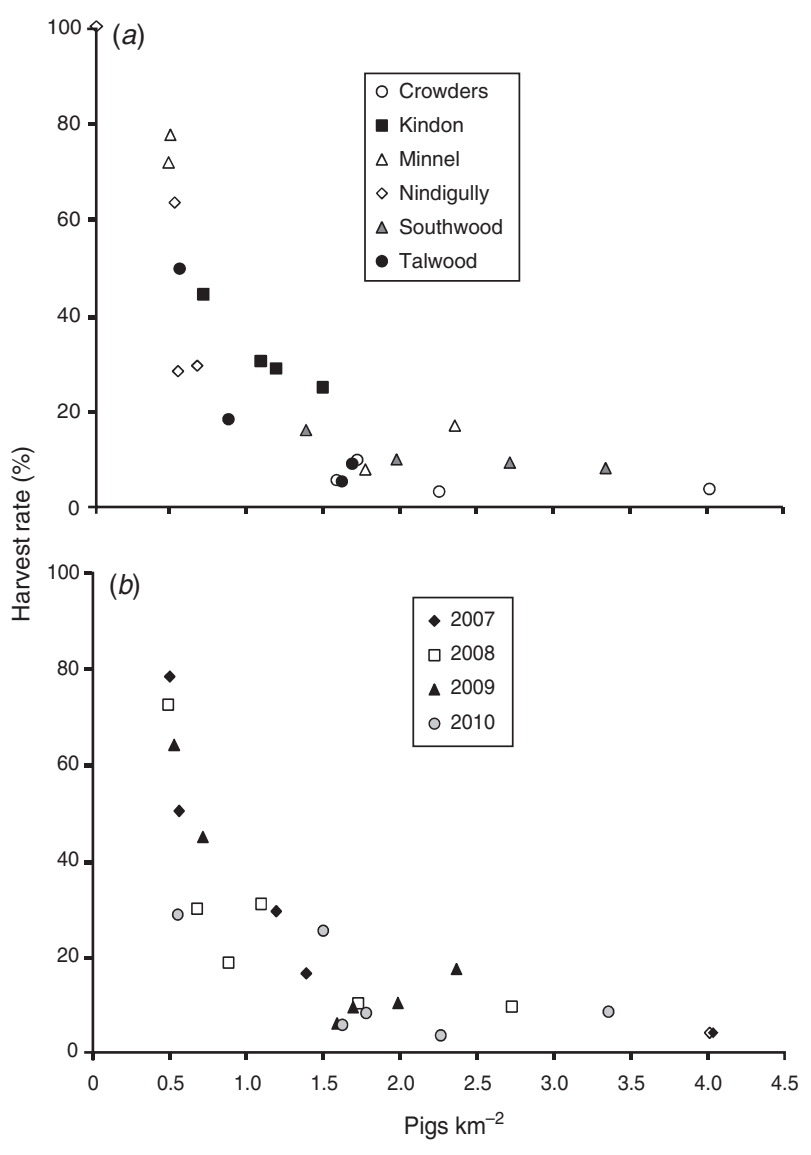

Fig. 8. The relationship between annual commercial harvest rate (\%) and mean (within a year) feral-pig density (pigs $\mathrm{km}^{-2}$ ) with (a) Queensland Murray-Darling Catchment (QMDC) sites or $(b)$ years identified.

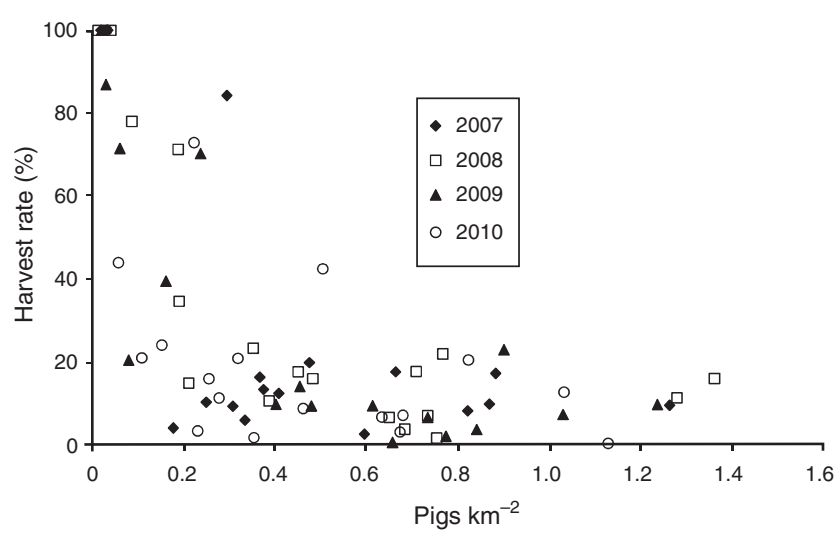

Fig. 9. The commercial harvest rate (\%) and feral-pig density $\left(\right.$ pigs km $\left.{ }^{-2}\right)$ for the regional survey blocks, 2007-10. Note: excludes blocks where no feral pigs were observed on survey.

on these sites. Additionally, two-group randomisation tests (Manly 1991) on the rates of increase on all sites were not significantly different from zero for each year $(P=0.77)$ or over the entire study period $(P=0.86)$, indicating stable populations.

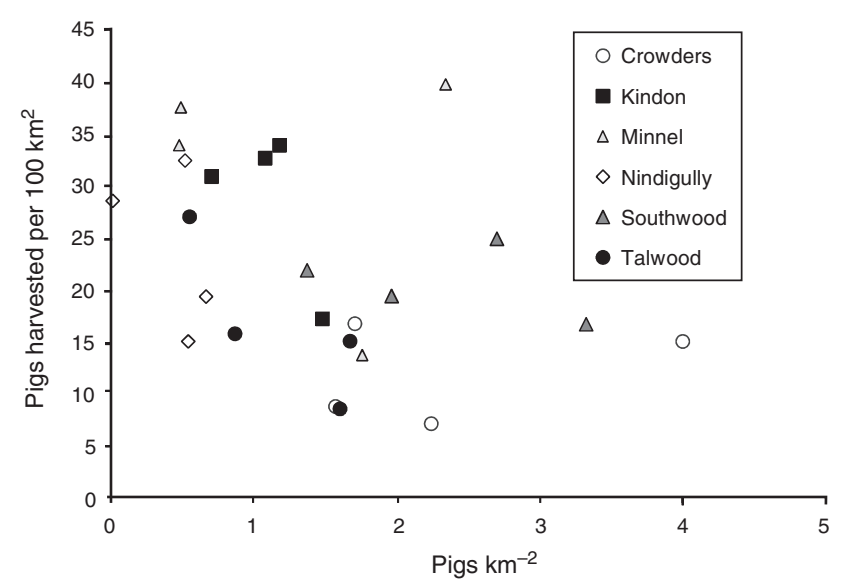

Fig. 10. The relationship between the number of pigs harvested by commercial operators per $100 \mathrm{~km}^{2}$ and feral pig density $\left(\right.$ pigs km${ }^{-2}$ ) on the Queensland Murray-Darling Catchment (QMDC) study sites.

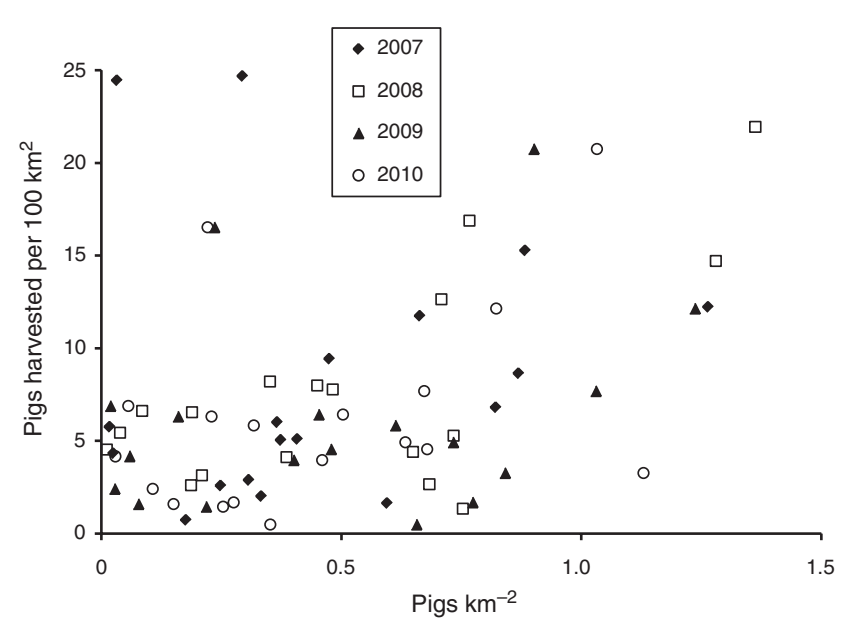

Fig. 11. The relationship between the number of pigs harvested by commercial operators per $100 \mathrm{~km}^{2}$ and feral-pig density (pigs km${ }^{-2}$ ) on the regional survey blocks.

\section{Discussion}

The present study is the first to use empirical data to assess the impact of commercial harvesting on feral-pig abundance in Australia. Other studies have merely discussed the potential for harvesting as a control technique (Ramsay 1994; Choquenot et al. 1995) or used modelling to hypothesise conditions under which control (or harvest) would work (Hone 2012), all in the absence of measured harvest rates.

Our results showed that, at current harvest rates, commercial harvesting is generally ineffective at reducing the abundance of feral pigs. The harvest rates for the QMDC sites and regional survey blocks would generate only modest reductions in the population size if maintained in the long term. In the shorter term, harvest rates fluctuated widely. The periods when harvest rates exceeded potential replacement levels were isolated occurrences and were not maintained across sites and years, and so populations would be able to recover quickly. 
Table 1. Mean observed annual exponential rates of increase (observed) over the 2.5-year study period (November 2007April 2010) and mean annual potential rates of increase without harvesting (potential)

Standard errors are shown in parentheses

\begin{tabular}{lccccrr}
\hline Parameter & Crowders & Kindon & Minnel & Nindigully & Southwood & Talwood \\
\hline Observed & $-0.177(1.12)$ & $0.019(0.14)$ & $0.461(2.77)$ & $1.29(1.61)$ & $0.411(0.34)$ & $0.376(0.25)$ \\
Potential & $-0.101(1.10)$ & $0.29(0.03)$ & $1.41(2.36)$ & $1.82(1.69)$ & $0.57(0.32)$ & $0.548(0.29)$ \\
\hline
\end{tabular}

Moreover, harvest rates were elevated only at low densities. Although these harvest rates may be sufficiently high to hold populations at low densities, the population is likely to escape this entrapment following a flush in food supply or a reduction in harvest effort. Furthermore, it is uneconomic to process small animals (Ramsay 1994) with the price paid per kg increasing with greater carcass weight. Therefore, harvesting off-take is biased towards larger animals, and probably males, which would reduce the overall effect of the harvest on population size; however, supporting data are lacking.

Our data indicated that current harvest rates would have to be significantly increased, or be sustained for extended periods to substantially reduce population size. It is widely reported that pig populations can quickly recover from any short-term density reductions, through increased reproduction and immigration (Choquenot et al. 1996; Hanson et al. 2009). Long-term reductions in density appear difficult to achieve, given market(demand-) and/or supply-driven conditions. Commercial harvesting of feral pigs has been undertaken in Australia since 1980, when changes to regulations facilitated the export of game meat (Ramsay 1994). The domestic market is insignificant, with most animals exported to European countries and packaged as 'wild boar' (Forsyth and Parkes 2004). The number exported is highly dependent on the demand from Europe, although poor seasonal conditions in Australia can also reduce the supply (quantity and quality) of animals harvested. The wild-boar harvesting industry remains highly volatile (B. Pearse, Australian Quarantine Inspection Service, pers. comm. 2012). Recently, the industry has suffered from intermittent closures of processing plants, reductions in numbers harvested and prices paid as competition from European countries, and unfavourable international exchange rates reduce demand for Australian product. It currently remains uneconomic for commercial processors to export wild boar, resulting in no field off-take in Queensland in 2013 (D. Church, Game Meat Processing, pers. comm. 2013).

Harvest off-take is also restricted by harvester access, which is affected by the road network, vegetation, and short-term (e.g. flood) and longer-term (e.g. drought) environmental fluctuations that influence the condition, and abundance and distribution of animals (Ramsay 1994; Forsyth and Parkes 2004). Other factors that influence supply include the number and distribution of field harvesters and field chiller depots, which tend to be correlated with demand for products (i.e. price paid; Ramsay 1994). The interaction between varying supply and demand results in wildly fluctuating changes in field off-take, and, subsequently, numbers processed. For example, processor throughput (i.e. the number of pigs processed for the export market) from 2001 to 2011 ranged between 73000 and 322000 carcasses per year (Australian Quarantine Inspection Service, unpubl. data).
There may be several mechanisms available to increase harvester off-take, including inflating the price of harvested animals through subsidies. In a modelling example, Choquenot et al. (1995) suggested that increasing the price paid for pigs would increase the distance from a chiller that harvesting remained profitable, effectively increasing the harvest area. Ramsay (1994) also argued that increasing prices results in increases in harvesting pressure, and a subsequent expansion of harvesting into more remote areas. Regardless of the mechanisms driving the fluctuations in harvest off-take, it is clear that such yearly variations make it difficult for commercial harvesting to consistently remove enough of the population to substantially reduce population size in the longer term.

Ultimately pest control needs to be assessed on the ability to reduce pest damage, not pest abundance (Braysher 1993), although the two are inextricably linked (Hone 1994). Although harvesting may suppress density only temporarily, this may be sufficient to reduce damage to acceptable levels. This may be true where the resources being damaged are particularly at risk during a certain time or life-cycle stage (e.g. lambs or field crops), and densities of predators can be reduced during this period. However, little data are available to determine density-damage relationships, and therefore determine the effectiveness of control campaigns at reducing damage to acceptable levels (Hone 2012). Despite these deficiencies, the ability of commercial harvesting to reduce damage will be limited by the ability to reduce density, and the area over which reductions can be achieved (Choquenot et al. 1995). Results from our study suggested that density reductions are temporary and limited in area, given it becomes uneconomic to harvest beyond a certain distance from the chiller (Choquenot et al. 1995). Spatial coverage of field chillers is also heavily focussed in southern Queensland and northern New South Wales, leaving more isolated areas unable to be harvested profitably, if at all. Areas where harvesting is limited would effectively provide a 'refuge', allowing resident animals to escape control, and also potentially act as a reservoir for immigration into more intensively harvested areas. Although harvest intensity is likely to be 'clumped', with some areas being harvested more heavily than others, density is likely to fall below a threshold where it is unprofitable to harvest, as predicted by predator-prey theory (Holling 1959). Given these spatial considerations and the likely temporary reductions resulting from intermittent heavy harvesting over time, it is unlikely that commercial harvesting in the absence of conventional control techniques could be used for reducing pig damage in the longer term.

There are some caveats to this conclusion. In the present study, we assumed that logistic growth occurs in response to removals, which is supported empirically (in wild boar, see 
Eberhardt et al. 2008) and often assumed (e.g. Pech and Hone 1988; Hone 2012), but, in reality, is overly simplistic. In a fluctuating environment, carrying capacity varies among years, resulting in a lower average population size (Hone 2012). The MSY will also be lower in absolute terms and as a percentage of population size (Caughley and Sinclair 1994; Grigg and Pople 2001). The effects of harvesting will, thus, have been underestimated here.

Some of the fluctuations in pig numbers observed on the study sites are likely to be responses to changes in food supply, but this can be difficult to disentangle from other factors. Natural mortality was not monitored in the present study and there were no 'nil-treatment' sites that lacked anthropogenic mortality. Other control was undertaken on all QMDC study sites (either ad hoc or coordinated control) during the study period, which would have contributed to a suppression in population size (Gentle et al. 2011). During drought, harvest mortality is likely to be compensated because many harvested animals were destined to die anyway (or have freed up resources for others to survive). Conversely, when food is abundant, harvest mortality is more likely to be additive.

Caution also needs to be taken in interpreting the estimated harvest rates. Aerial survey estimates of pig density were imprecise (see Tables S1 and S2) and so the associated harvest rates would also have broad confidence intervals. This will partly explain the physiologically impossible rates of increase in some cases, although immigration could have been a factor. Harvest data were collated and grouped by field chiller location, and the 'catchment area' was estimated from buffering distances from these locations. The number harvested for the area surrounding each chiller location is assumed to be uniformly distributed within each buffer area. This may not be the case and it is likely that harvesting is 'clumped' into specific areas on the basis of local access and environmental conditions. Although this is potentially a problem for the relatively small QMDC sites, it is less so for the regional survey blocks where any non-uniform distribution should have been 'evened out' on the broader scale. Nevertheless, the estimated commercial harvest rates for the QMDC sites each year (14.5-46.0\%) are on average higher than those recorded for the nearby Westmar regional survey block (12.8-23.1\%).

A greater range of pig densities is required to thoroughly assess the relationship between harvest off-take or rate and density. Unfortunately harvest data were available only for 2007-10 when densities were relatively low on the survey blocks. Nevertheless, the decline in harvest rate with increasing density reported here is expected from predator-prey theory. It fits a Type II functional response (Holling 1959) that is reported for several wildlife populations (Caughley and Sinclair 1994) and is observed for harvesting kangaroos in Queensland (Pople 2006) and shooting pigs by helicopter (Hone 1990; Choquenot et al. 1999). Unless more harvesters enter the industry, harvest off-take will remain effectively limited (or saturated) at higher pig densities, reducing the harvest rate.

The results of the present study showed that, on the basis of empirical harvest data from processing companies and aerial survey estimates of population size, commercial harvest rates are generally low, well below the likely replacement levels and are not maintained across sites and years. At current harvest rates, commercial harvesting is ineffective for landscape-scale reduction of feral-pig populations. The harvest off-take and scale of commercial harvesting would need to be significantly increased or supplemented with other lethal control (such as trapping, baiting and aerial shooting) to reduce feral-pig populations in the long term. These findings will help land managers and policy-makers determine whether harvesting should be encouraged (e.g. through incentives or subsidies) to increase harvest rates, or integrated with other control techniques to achieve pest management objectives.

\section{Acknowledgements}

This project was approved under the Department of Agriculture, Fisheries and Forestry Animal Ethics Committee (CA 2007/09/211). Many thanks to James Speed, Darren Marshall, Aaron Prendergast, Nathan Stephenson and David Aster for assistance with the aerial surveys. Thanks to the various processing companies and David Aster for collating harvest data, and to Neal Finch from the Department of Environment and Heritage Protection for access to the raw aerial-survey data. We are grateful to two anonymous referees for providing comments that improved the manuscript.

\section{References}

Allen, L., Hynes, R., and Thompson, J. (1995). Is commercial harvesting compatible with effective control of pest animals and is this use sustainable? In 'Conservation through sustainable use of wildlife'. (Eds G. C. Grigg, P. T. Hale and D. Lunney.) pp. 259-266. (Centre for Conservation Biology, The University of Queensland: Brisbane)

Beard, L. A. (1999). Training observers. Australian Zoologist 31, 287-291.

Bengsen, A. J., Gentle, M. N., Mitchell, J. L., Pearson, H. E., and Saunders, G. R. (2013). Impacts and management of wild pigs Sus scrofa in Australia. Mammal Review. doi:10.1111/mam.12011

Benson, R. (1980). Evaluating feral pig damage and costs of control in western New South Wales. Research workpaper no. 120. Division of Marketing and Economics, Department of Agriculture, Sydney.

Braysher, M. (1993). 'Managing Vertebrate Pests: Principles and Strategies.' (Bureau of Rural Sciences: Canberra.)

Buckland, S. T., Anderson, D. R., Burnham, K. P., and Laake, J. L. (1993). 'Distance Sampling: Estimating Abundance of Biological Populations.' (Chapman and Hall: London.)

Caley, P. (1993). The ecology and management of feral pigs in the 'wet-dry' tropics of the Northern Territory. M.Appl.Sc. Thesis, University of Canberra.

Caughley, G. (1980). 'Analysis of Vertebrate Populations.' (John Wiley and Sons: New York.)

Caughley, G. (1987). Introduction to the sheep rangelands. In 'Kangaroos: their Ecology and Management in the Sheep Rangelands of Australia'. (Eds G. Caughley, N. Shepherd and J. Short.) pp. 1-13. (Cambridge University Press: Cambridge, UK.)

Caughley, G. (1994). Directions in conservation biology. Journal of Animal Ecology 63, 215-244. doi:10.2307/5542

Caughley, G., and Sinclair, A. R. E. (1994). 'Wildlife Ecology and Management.' (Blackwell Scientific Publications: London.)

Choquenot, D. (1995). Assessing visibility bias associated with helicopter counts of feral pigs in Australia's semi-arid rangelands. Wildlife Research 22, 569-578. doi:10.1071/WR9950569

Choquenot, D. (1998). Testing the relative influence of intrinsic and extrinsic variation in food availability on feral pig populations in Australia's rangelands. Journal of Animal Ecology 67, 887-907. doi:10.1046/j.1365-2656.1998.6760887.x

Choquenot, D., O'Brien, P., and Hone, J. (1995). Commercial use of pests: can it contribute to conservation objectives? In 'Conservation through sustainable use of wildlife'. (Eds G. C. Grigg, P. T. Hale and D. Lunney.) 
pp. 251-258. (Centre for Conservation Biology, The University of Queensland: Brisbane.)

Choquenot, D., McIlroy, J., and Korn, T. (1996). 'Managing Vertebrate Pests: Feral Pigs.' (Bureau of Resource Sciences, Australian Government Publishing Service: Canberra.)

Choquenot, D., Hone, J., and Saunders, G. (1999). Using aspects of predator-prey theory to evaluate helicopter shooting for feral pig control. Wildlife Research 26, 251-261. doi:10.1071/WR98006

Clancy, T. F., Pople, A. R., and Gibson, L. A. (1997). Comparison of helicopter line transects with walked line transects for estimating densities of kangaroos. Wildlife Research 24, 397-409. doi:10.1071/ WR96103

Eberhardt, L. L., Breiwick, J. M., and Demaster, D. P. (2008). Analyzing population growth curves. Oikos 117, 1240-1246. doi:10.1111/j.00301299.2008.16402.x

Fewster, R. M., Southwell, C., Borchers, D. L., Buckland, S. T., and Pople, A. R. (2008). The influence of animal mobility on the assumption of uniform distances in aerial line-transect surveys. Wildlife Research 35, 275-288. doi:10.1071/WR07077

Fordham, D., Georges, A., Corey, B., and Brook, B. (2006). Feral pig predation threatens the indigenous harvest and local persistence of snake-necked turtles in northern Australia. Biological Conservation 133, 379-388. doi:10.1016/j.biocon.2006.07.001

Forsyth, D. M., and Parkes, J. P. (2004). Maximising the conservation benefits of the commercial goat industry in Australia, Final report for the Australian Government Department of the Environment and Heritage, Canberra.

Gentle, M., Pople, A., Speed, J., and Aster, D. (2011). Assessing the role of harvesting in feral pig (Sus scrofa) management. Final report to Blueprint for the Bush. Biosecurity Queensland, Department of Employment, Economic Development and Innovation, Toowoomba, Qld.

Giles, J. (1980). The ecology of feral pigs in western New South Wales. Ph. D. Thesis, University of Sydney.

Gong, W., Sinden, J., Braysher, M., and Jones, R. (2009). 'The Economic Impacts of Vertebrate Pests in Australia.' (Invasive Animals Cooperative Research Centre: Canberra.)

Grigg, G. C., and Pople, A. R. (2001). Sustainable use and pest control in conservation: kangaroos as a case study. In 'Conservation of Exploited Species'. (Eds J. Reynolds, G. Mace, K. Redford and J. Robinson.) pp. 403-423. (Cambridge University Press: Cambridge, UK.)

Hacker, R. B., McLeod, S. R., and Druhan, J. (2003). Final report for project \#D8003. Evaluating alternative management strategies for kangaroos in the Murray Darling Basin. NSW Department of Agriculture, Dubbo, NSW.

Hanson, L. B., Mitchell, M. S., Grand, J. B., Jolley, D. B., Sparklin, B. D., and Ditchkoff, S. S. (2009). Effect of experimental manipulation on survival and recruitment of feral pigs. Wildlife Research 36, 185-191. doi:10.1071/WR08077

Holling, C. S. (1959). The components of predation as revealed by a study of small-mammal predation of the European pine sawfly. Canadian Entomologist 91, 293-320. doi:10.4039/Ent91293-5

Hone, J. (1990). Predator-prey theory and feral pig control, with emphasis on evaluation of shooting from a helicopter. Australian Wildlife Research 17, 123-130. doi:10.1071/WR9900123

Hone, J. (1994). 'Analysis of Vertebrate Pest Control.' (Cambridge University Press: Cambridge, UK.)

Hone, J. (2002). Feral pigs in Namadgi National Park, Australia: dynamics, impacts and management. Biological Conservation 105, 231-242. doi:10.1016/S0006-3207(01)00185-9
Hone, J. (2012). 'Applied Population and Community Ecology: the Case of Feral Pigs in Australia.' (Wiley-Blackwell: Oxford, UK.)

Hone, J., and Pedersen, H. (1980). Changes in a feral pig population after poisoning. In 'Proceedings of the 9th Vertebrate Pest Conference'. (Ed. J. P. Clark.) pp. 176-182. (University of California: Davis, CA.)

Hone, J., Duncan, R. P., and Forsyth, D. M. (2010). Estimates of maximum annual population growth rates $\left(r_{\mathrm{m}}\right)$ of mammals and their application in wildlife management. Journal of Applied Ecology 47, 507-514. doi:10.1111/j.1365-2664.2010.01812.x

Laake, J. L., and Borchers, D. L. (2004). Methods for incomplete detection at distance zero. In 'Advanced Distance Sampling'. (Eds S. T. Buckland, D. R. Anderson, K. P. Burnham, J. L. Laake, D. L. Borchers and L. Thomas.) pp. 281-306. (Oxford University Press: Oxford, UK.)

Laake, J. L., Dawson, M. J., and Hone, J. (2008). Visibility bias: mark-recapture, line-transect, or both? Wildlife Research 35, 299-309. doi:10.1071/WR07034

Manly, B. F. J. (1991). 'Randomization and Monte Carlo Methods in Biology.' (Chapman and Hall: London.)

McLeod, R. (2004). 'Counting the Cost: Impact of Invasive Animals in Australia 2004.' (Cooperative Research Centre for Pest Animal Control: Canberra.)

Mitchell, J. (2008). 'Feral Pig Control: a Practical Guide to Pig Control in Queensland.' (Queensland Department of Primary Industries \& Fisheries: Brisbane.)

Mitchell, J. (2010). Experimental research to quantify the environmental impact of feral pigs within tropical freshwater ecosystems. Final report to the Department of the Environment, Water, Heritage and the Arts, Canberra.

Pavlov, P. M. (1980). The diet and general ecology of the feral pig (Sus scrofa) at Girilambone, NSW. M.Sc. Thesis, Monash University, Melbourne.

Pavlov, P., Hone, J., Kilgour, R., and Pedersen, H. (1981). Predation by feral pigs on Merino lambs at Nyngan, New South Wales. Australian Journal of Experimental Agriculture and Animal Husbandry 21, 570-574. doi:10.1071/EA9810570

Pech, R. P., and Hone, J. (1988). A model of the dynamics and control of foot and mouth disease and feral pigs in Australia. Journal of Applied Ecology 25, 63-77. doi:10.2307/2403610

Pople, A. R. (2006). Modelling the spatial and temporal dynamics of kangaroo populations for harvest management. Final report to the Department of Environment and Heritage, Canberra.

Pople, A., Evans, M. C., Farroway, L., Gilroy, J., Grigg, G., Lundie-Jenkins, G., and Payne, N. (2010). Using harvest statistics to monitor temporal variation in kangaroo density and harvest rate. In 'Macropods: the Biology of Kangaroos, Wallabies and Rat-kangaroos'. (Eds G. Coulson and M. D. B. Eldridge.) pp. 371-397. (CSIRO Publishing: Melbourne.)

Ramsay, B. J. (1994). 'Commercial Use of Wild Animals in Australia.' (Bureau of Resource Sciences Australian Government Publishing Service: Canberra.)

Thomas, L., Buckland, S.T., Rexstad, E.A., Laake, J. L., Strindberg, S., Hedley, S. L., Bishop, J. R.B., Marques, T. A., and Burnham, K. P. (2010). Distance software: design and analysis of distance sampling surveys for estimating population size. Journal of Applied Ecology 47, 5-14. doi:10.1111/j.1365-2664.2009.01737.x

Tracey, J. (2006). An evaluation of aerial pig (Sus scrofa) baiting using helicopter surveys. Final report to the Invasive Animals Cooperative Research Centre, NSW Department of Primary Industries, Orange.

Woodall, P. F. (1983). Distribution and population dynamics of dingoes (Canis familiaris) and feral pigs (Sus scrofa) in Queensland, 1945-1976. Journal of Applied Ecology 20, 85-95. doi:10.2307/2403377 